Onkologe 2005 - 11:657 DOI 10.1007/s00761-005-0908-3

Online publiziert: 11. Juni 2005 - @ Springer Medizin Verlag 2005

A. Gaisser - Deutsches Krebsforschungszentrum

\title{
Internationale Konferenz St. Gallen, 26.-29.01.2005: „Primary Therapy of Early Breast Cancer". Schlaglichter aus dem Vortragsprogramm: Was ist neu seit St. Gallen 2003?
}

\author{
Der Onkologe (2005) 11:446-456
}

D schen Fehler wurden versehentlich zwei Abbildungen vertauscht. Die korrekte Reihenfolge lautet:

Darüber hinaus weist die Autorin auf einen Fehler in Tabelle 3 hin. Unter niedriges Risiko, nodalnegativ heißt es richtig: und $\mathrm{G}_{1}$ (bei <1 cm auch $\mathrm{G}_{3}$ ).
Korrespondierender Autor A. Gaisser

Deutsches Krebsforschungszentrum, Krebsinformationsdienst KID,

Im Neuenheimer Feld 280, 69120 Heidelberg E-Mail: A.Gaisser@dkfz.de

Wir bitten die Fehler zu entschuldigen.

Die Redaktion

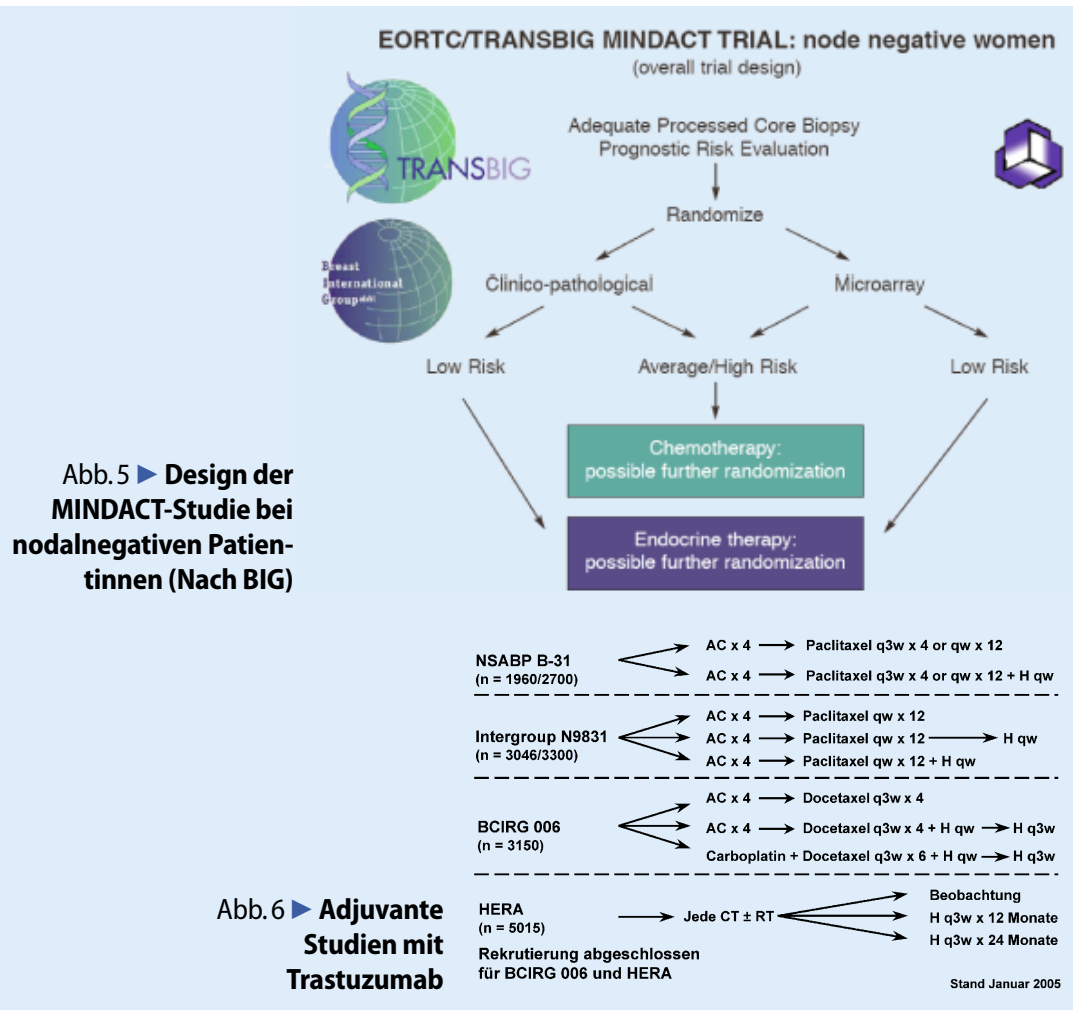

